Classification

Physics Abstracts

$07.55-91.60$

\title{
Measurement of magnetic susceptibilities of minerals and rocks by a simple induction device
}

\author{
G. Alzetta, G. Villa \\ Dipartimento di Fisica dell'Universitá, Pisa, Italy
}

and S. Battaglia

Istituto per il Trattamento dei Minerali del C.N.R., Roma, Italy

(Reçu le 24 juin 1983, révisé le 14 novembre, accepté le 18 novembre 1983)

\begin{abstract}
Résumé. - L'appareil présenté dans cet article permet d'effectuer des mesures rapides et précises de la susceptibilité paramagnétique des minéraux et des roches. Son principe repose sur la détection de la variation du flux magnétique produite dans un aimant lorsqu'on insère dans son entrefer l'échantillon à examiner. Cet appareil se distingue particulièrement par sa simplicité, sa solidité et sa versatilité. De plus, il se prête bien à l'application des méthodes de traitement du signal pour atteindre des sensibilités très élevées.
\end{abstract}

Abstract. - A device has been developed for rapid and accurate measurement of paramagnetic susceptibilities of minerals and rocks. It works on detection of the flux variation produced in a permanent magnet by inserting in the gap the specimen under investigation. Simplicity, ruggedness and versatility are the main features of the apparatus which allows also the use of averaging techniques to reach high sensitivities.

\section{Introduction.}

Accurate measurements of magnetic susceptibilities of rocks, sands, polycrystalline samples, etc., are undoubtly of interest in modern research on geophysical properties of the earth crust and can be very useful for practical testing of the increase in the magnetic content during the process of refinement and enrichment of minerals. In our opinion this type of measurements are not of common use in the geophysical laboratories owing to the rather bothersome and time consuming instruments usually adopted in physics for precise measurements on homogeneous and wellshaped samples.

A less elaborated apparatus that allows rapid and accurate measurements would benefit of a more popular use in geophysical research and would contribute to a better knowledge of the susceptibility of the different rocks, so important now for a correct interpretation of the data on the magnetic field over the earth's crust.

Susceptibility is defined by the relation

$$
x=I / H,
$$

i.e. the ratio between the intensity of magnetization of a body and the intensity of the magnetizing field. Usually in the tables the values of

$$
\begin{array}{cl}
\chi & =x / d \quad \text { (specific susceptibility) and } \\
\chi_{\mathrm{m}} & =\chi \cdot M \quad \text { (molar susceptibility), }
\end{array}
$$

with $d$, density and $M$, molecular weight (in c.g.s. units), are reported.

$x$ is a dimensionless tensor, but owing to the fact that we take into consideration in the following only powders or polycristalline mixtures or isotropic samples, we consider it as a scalar.

The most precise methods so far used for the measure of susceptibility involve a measurement of the force acting on the sample suspended in an inhomogeneous magnetic field (Schwarz [3]) : it is a very sensitive technique which has been extensively employed for measures of absolute values of susceptibility of solids. However, owing to the use of delicate balances and stringent precision in positioning the sample, the method requires particular care. Moreover the method works well with small and well-shaped samples, but it is rather objectionable when used for non-homogeneous and rough materials as granulates, rocks, sands, etc. 
Induction methods, as typically used by Weiss and Forrer [6], involve observation of the voltage induced in a detection coil by a change in the magnetic flux due to the sample, and seems to be best suited to meet different experimental requirements of the geologist or mineralogist (Bates, [1]).

Instead of using ballistic (Weiss and Forrer [5]) or vibrating-coil (Smith [4]), or vibrating-sample (Foner [2]) induction techniques, we have found that a more simple and convenient arrangement is to drive the sample through the gap between the tips of a permanent magnet, and to detect the voltage induced in coils wound on the pole caps - taking advantage of modern electronic low-noise amplification.

\section{Design of the apparatus.}

A schematic of the experimental apparatus is reported in figure 1. A lucite plate, $30 \mathrm{~cm}$ diameter and $1 \mathrm{~cm}$ thick, supported by a vertical non-magnetic stainless steel shaft, turns in an horizontal plane with a constant speed, driven by a d.c. motor. In symmetric position with respect to the centre, two circular holes, $2 \mathrm{~cm}$ diameter, allow positioning of two polyethylene containers for the specimen under investigation and a reference sample. Due to rotation of the plate, the containers, of cylindrical shape and diameter equal to that of pole caps, cross alternatively the gap of the magnet.

For samples with a susceptibility $\chi$ different from that of the plate, a variation of flux takes place that gives rise to an induced voltage in two coils, 300 turns each, wound around the caps and connected in series.

The induced voltage can be directly monitored by an oscilloscope with a millivolt sensitivity. A very crude estimate of the flux change can be done if we suppose the fringing field negligible, and the main magnetic field confined in the cylindrical volume of the gap, of height $h$ and radius $R$, and uniform in that place. If a cylindrical sample of same radius $R$, height $\Delta h$ and susceptibility $x$ is placed inside the gap with its plane faces parallel to the caps surfaces, the field has to undergo a change owing to the fact that the field $B_{0}$ in absence of the sample has increased to the value

$$
B=B_{0}+\mu_{0} I=B_{0}(1+x),
$$

where $I$ is the intensity of magnetization of the sample.

When the sample is moved from the outside to the inside of the gap, the variation of magnetic flux $\Delta \Phi(B)$ can be assumed to be proportional to the superposed area $A$ of container and cap (Fig. 2), and given by

$$
\Delta \Phi(B)=\alpha B_{0}(\Delta h / h) x A
$$

where

$$
\begin{aligned}
& A=2 R^{2}\left(\theta-\frac{1}{2} \sin 2 \theta\right)= \\
& \quad=2 R^{2}\left(\arccos (r / R)-(r / R) \sqrt{1-(r / R)^{2}}\right) .
\end{aligned}
$$

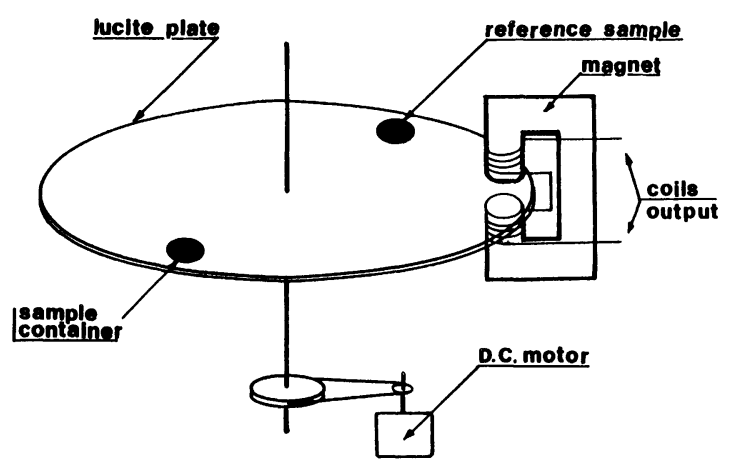

Fig. 1. - Schematic view of the experimental set-up.

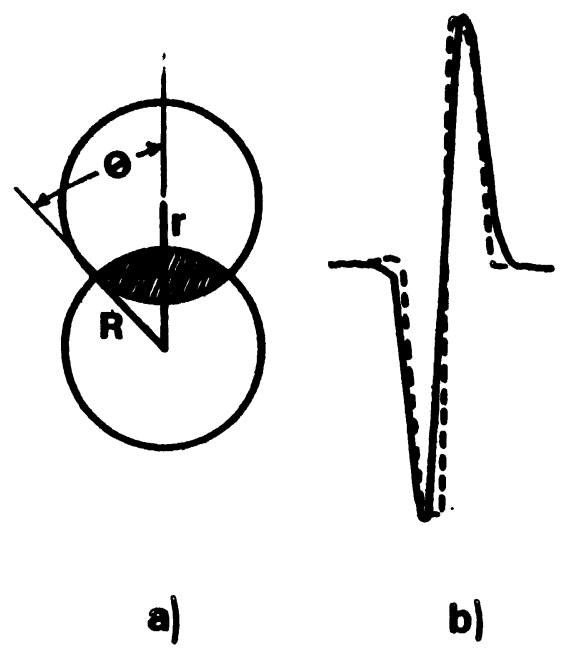

Fig. 2. - a) Geometry of pole cap and sample for calculating the magnetic flux variation. b) Calculated (---) and experimental (-) curve.

$2 r$ is the distance between the centres of container and pole cap (Fig. $2 a$ ), $\Delta h / h$ the filling factor of the gap, and $\alpha$ is a coefficient which depends on the slope $\mathrm{d} B / \mathrm{d} H$ at the working point of the magnet caracteristic : in our working conditions $\chi \ll 1$, and we can assume $\alpha$ as a constant.

If distance $2 r$ linearly depends on time, $\mathrm{d} r=v \cdot \mathrm{d} t$, with $v$ a constant : then the time derivative of $\Phi(B)$ can be obtained by simple differentiation of (1)

$$
\mathrm{d} \Phi(B) / \mathrm{d} t=\alpha B_{0}(\Delta h / h) x v(\mathrm{~d} A / \mathrm{d} r)
$$

In figure $2 b$ a plot of this function is superposed to an experimental curve; the difference in shape between the two curves is mainly due to non-uniformity of the field between the caps and to the lack in the above calculation of the fringing field that broadens the effective magnetic field on the sample. Nevertheless, owing to equal dimensions of the two containers and to their same distance from the centre of the turning 
plate, a same path inside the magnetic field for the two containers is assured : a fact that allows to assume similitude between the signal of different samples, and to obtain the ratio between the susceptibilities of the two samples by simply taking the ratio of the amplitude of the two signals. As reference sample we have used constantly $\mathrm{Nd}_{2} \mathrm{O}_{3}$, due to its well known susceptibility and purity.

It must be pointed out that our measurements have been corrected taking into consideration the diamagnetic value $\chi$ (luc) of lucite : in our case $\chi$ (luc) $=$ $-0.80 \times 10^{-6}$.

As we can see from formula (2) the amplitude of the signal is proportional to the intensity of the magnetic field in the gap. In our case a permanent magnet produced by Indiana Steel Products Co., with $2 \mathrm{~cm}$ pole caps diameter and $2 \mathrm{~cm}$ wide gap, has been used. The field at the centre of the gap as measured by Hall device resulted to be about $5000 \mathrm{G}$. We wish to point out that in our arrangement we have tried different types of magnets, but we have found that magnet dimension and profile are not at all critical, nor they have been optimized for a maximum voltage output.

\section{Discussion and results.}

The sensitivity of the apparatus can be very high owing to the low thermal noise voltage of the coils at the frequencies of the signals. Main sources of noise have been found to be due to microphonic vibrations of the magnet and assembly, and to erratic spurious magnetic fields due mainly to the electric motor drive and circuits in the nearness of the apparatus. Such type of noise limits the sensitivity of our device to some parts in $10^{-7}$ when measured in c.g.s. units. This figure compares favorably with the sensitivities of usual systems.

Assuming as standard $\mathrm{Nd}_{2} \mathrm{O}_{3}, \chi_{\mathrm{m}}=10200 \times 10^{-6}$ c.g.s. units (as reported by Handbook of Chemistry and Physics, 48th ed., 1967-68, The Chemical Rubber Co., Cleveland, Ohio, U.S.A.) we have measured the susceptibility of some pure inorganic compounds. The precision of our device, as we have deduced from these measurements, is within $\pm 3 \%$.

The angular velocity of the plate was kept rather low (about two turns per second) in order to avoid possible vibration of assembly. It can obviously be increased in order to improve the sensitivity as can be seen again from formula (2), valid, as usually is the case for minerals, when the relaxation times for the magnetization are short enough compared with the transit time through the gap. It should also be pointed out that owing to the iteration of the signals at every turn of the plate, averaging techniques can be used which allow compensation of spurious voltages and increase sensitivity by a factor proportional to the square root of the number of turns done by the plate.
The device has been applied to measurements on minerals and rocks : some tests of linearity in function of the quantity of material have been performed with different samples. An example is reported in figure 3, which shows the response of the apparatus to different mixtures of $\mathrm{Nd}_{2} \mathrm{O}_{3}$ and $\mathrm{MnSO}_{4}$. In figure 4 some tests

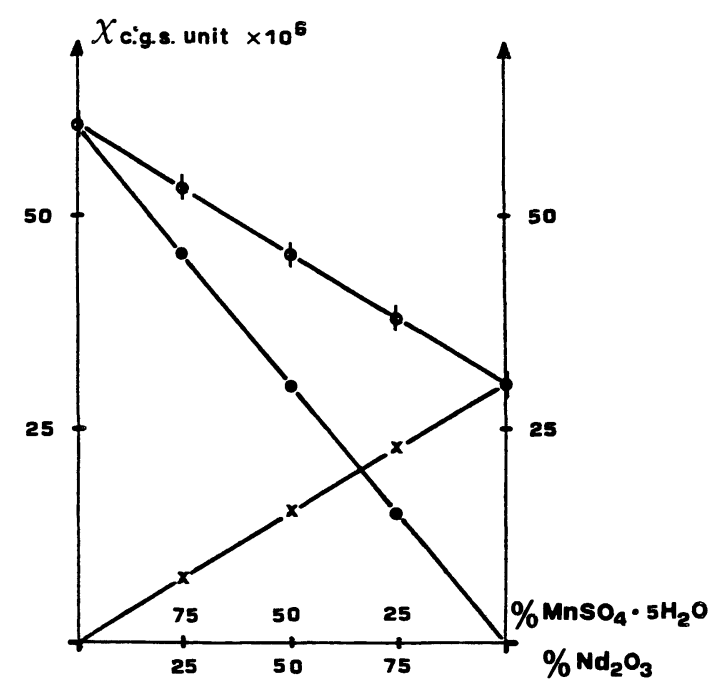

Fig. 3. - Test of linearity in measuring the susceptibilities of $\mathrm{Nd}_{2} \mathrm{O}_{3}$ and $\mathrm{MnSO}_{4} .5 \mathrm{H}_{2} \mathrm{O}$ mixtures. $\times$ and $\bullet$ : calculated susceptibilities of $\mathrm{Nd}_{2} \mathrm{O}_{3}$ and $\mathrm{MnSO}_{4} .5 \mathrm{H}_{2} \mathrm{O} . \phi$ : measured susceptibility of the mixtures (the vertical bar indicates the error).
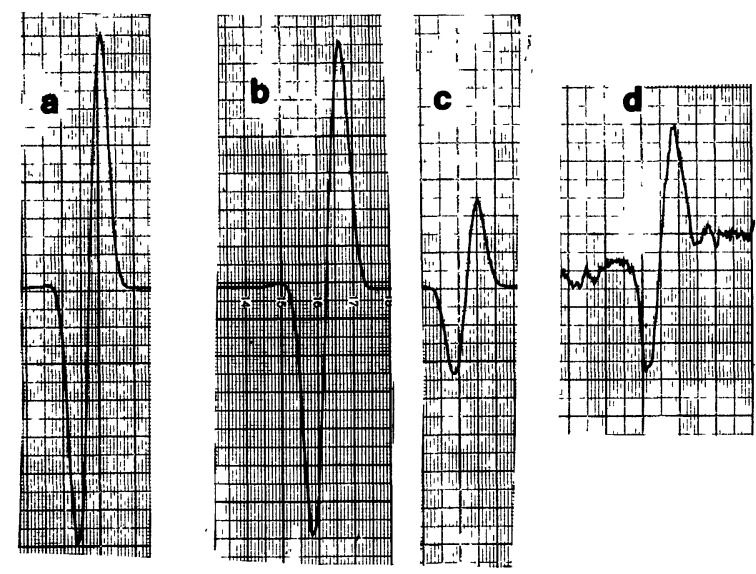

Fig. 4. - Typical responses of some types of rocks (susceptibilities in c.g.s. units). Vertical scale : $a$ ), b),c) $1 \mathrm{mV} / \mathrm{cm}$, d) $0.033 \mathrm{mV} / \mathrm{cm}$. Horizontal scale : $10 \mathrm{~ms} / \mathrm{cm}$. a) $\mathrm{Nd}_{2} \mathrm{O}_{3}$ (reference sample) : $\chi=30.3 \times 10^{-6}$, response of a $6.62 \mathrm{~g}$ sample. b) Olivin gabbro (Italian Northern Appennines) : $\chi=60.46 \times 10^{-6}$, response of a $3.20 \mathrm{~g}$ sample. $c$ ) Peridotitic nodule (Red Sea) : $\chi=16.62 \times 10^{-6}$, response of a $4.20 \mathrm{~g}$ sample. $d$ ) Limestone dolomite blend : $\chi=0.29 \times 10^{-6}$, response of a $2.75 \mathrm{~g}$ sample - in this case the correction for the non-negligible value of $\chi$ (lucite) must necessarily be applied. 
performed on typical rocks of the earth crust are reported. The susceptibility $\chi$ of powder samples ranges from low values as in the Limestone Dolomite Blend 403 (International Standard) to the middlerange values of a Peridotitic nodule from Zabargad (Red Sea), and of an Olivin Gabbro from Italian Appennines.

\section{Acknowledgments.}

The authors wish to express their appreciation to Prof. L. Leoni, Institute of Mineralogy of the University of Pisa, for providing the samples. Thanks are also due to Mr. F. Sbrana for his cooperation and help at various stages in this work.

\section{References}

[1] BATES, L. F., Modern Magnetism (Cambridge University Press) 1948.

[2] FONER, S., Versatile and sensitive vibrating-sample magnetometer. Rev. Sci. Instrum. 3 (1959) 548.

[3] SChwarz, E. J., A recording thermomagnetic balance. Geological Survey of Canada, Ottawa. Pap. 68-37 (1968).
[4] SмIтH, D. O., Development of a vibrating-coil magnetometer. Rev. Sci. Instrum. 27 (1956) 261.

[5] WeIss, P. and ForRer, R., Magnetisation of Nickel and the magnetocaloric effect. Ann. Phys. 5 (1926) 153.

[6] WeIsS P. and ForRer, R., Absolute saturation of Ferromagnetics in terms of the field and the temperature. Ann. Phys. 12 (1929) 297. 